Method From January until the end of March 2021 support was provided to the designated care home in the form of:

- A weekly virtual ward round. Members on the virtual ward round included a GP, the Lead Nurse from the care home, an Advanced Nurse Practitioner, a paramedic and a Palliative Care Nurse Specialist.

- The provision of regular telephone calls throughout the week was dependant on need from the care home.

- If there were any particular patients that the care home staff had concerns about a clinical nurse specialist would be available at weekends and bank holidays for advice and support.

- Telephone calls to relatives.

Results

- Prevention of patients being readmitted to the Acute NHS Trusts following the input from specialist palliative care.

- Quality symptom control provided for patients not for escalation.

- Quality end-of-life care.

- Support for care home staff.

Conclusion The specialist palliative care input made a positive contribution to the care of patients and also to the symptom control of those patients who were end-of-life. Staff felt supported in looking after these patients at a time when care home staff were generally feeling very isolated.

\section{P-70 THE EVOLVING ROLE OF RAPID RESPONSE CLINICAL NURSE SPECIALIST DURING THE COVID-19 PANDEMIC}

Ross Chirgwin. St Helena Hospice, Colchester, Essex

10.1136/spcare-2021-Hospice.88

Background Having access to a community non-medical prescriber (NMP) can enhance patient care by anticipating and responding quickly to symptom control issues at end-of-life and supporting patients to die within their preferred place of care (McGleish, Sivell, Nelson, 2015). With the predicted surge in demand that would overwhelm our local healthcare the end-of-life hub was expanded which included increased NMP capacity.

Aim To meet the predicated demand in services during the COVID-19 pandemic the end-of-life hub would have rapid response clinical nurse specialists (NMPs) available to rapidly assess and provide specialist palliative care advice and symptom control within the community.

Method All of the NMPs within the community team were redeployed to the end-of-life hub. By expanding the team this enabled access to NMPs seven days a week and at the height of the pandemic an NMP was available 24/7 for patients who required rapid assessment. Within the end-of-life hub there was also a quick implementation of access to emergency medications that the NMPs were able to obtain. This enabled the team to provide timely symptom control when accessing medications from a community pharmacy was not available.

Outcome Support was provided to patients who were COVID19 positive or with a life-limiting illness that required rapid assessment either within their own home and critically those within nursing or residential placements. Assessment was often challenging due to limited information being available and therefore detailed assessment was needed to ensure the best outcome for each individual.
Conclusion The NMPs have now been permanently redeployed to the end-of-life hub and continue to provide cover seven days a week. The role has been critical in supporting patients within the community by enabling rapid assessment, symptom management and allowing patients to die within their preferred place of care.

\section{P-71 END-OF-LIFE HUB- COORDINATING END-OF-LIFE CARE DURING COVID-19 PANDEMIC}

Ross Chirgwin, Nicky Coombes. St Helena Hospice, Colchester, UK

10.1136/spcare-2021-Hospice.89

Background With the concern that demand would overwhelm our local healthcare services our hospice in the home team was expanded to develop an end-of-life care hub. The hub would lead and co-ordinate all non-acute hospital end-of-life care within the locality.

Aim The end-of-life hub would ensure the efficient use of the entire end-of-life resources across the locality and enable timely access to care. This involved working in collaboration with external services including primary care, community nursing, ambulance service and local community hospitals.

Method The end-of-life hub is supported by call handlers, senior staff nurses, healthcare assistants and clinical nurse specialists and was operational 24/7. The main functions of the hub included:

- Single point of contact for all end-of-life matters for professionals, patients and family members 24/7.

- Receive diverted call from NHS 111 and out-of-hours services where patients were either COVID-19 positive and not suitable for acute admission or approaching end-of-life.

- Provision of 24/7 medical advice and specialist palliative care prescribing capability.

- Provision of 24/7 rapid response visiting in partnership with community nursing.

- Coordinating flow through all non-acute community hospital admissions for end-of-life care including medical and pharmacy support.

- Coordinating the expanding virtual ward service.

- Liaising with central continuing healthcare team on care that could not be provided through virtual ward.

- Coordinate the electronic end-of-life register (My Care Choices).

Outcome The end-of-life hub received a total of 45,670 calls into the service over the past year. During this time a total of 4943 referrals were received and processed through the endof-life hub which coordinated their care and ongoing support within the locality.

Conclusion The end-of-life care hub continues to develop and remains a core service within the community to continue to increase our reach to serve our local population.

\section{P-72 TURNING THAT FROWN UPSIDE DOWN; THROUGH COVID-19 AND BEYOND}

Cathy Hunt. Garden House Hospice Care, Letchworth, UK

10.1136/spcare-2021-Hospice.90 
Background The hospice provides inpatient, outpatient and community services including a Continuing Healthcare (CHC) virtual ward. During COVID-19 the hospice suffered clinical staffing issues with immune-compromised staff isolating and volunteers unable to attend, while income-generation departments were furloughed. CHC beds were increased by $10 \%$ to facilitate hospital discharges.

Aims To enable the community team to continue to support palliative patients in their own homes and allow prompt discharge of hospital patients.

Method All furloughed staff were contacted and offered the opportunity to support the clinical teams. This included outpatient clinical staff and non-clinical staff. The education department delivered intensive training sessions including clinical mandatory training and core personal care skills leading to the role of Clinical Support Worker (CSW). However, working a trial shift for some proved too demanding emotionally, psychologically, or physically.

Results Caring for COVID-19 positive patients had a large psychological impact on the team. However, no COVID-19 transfer was identified from a patient or between colleagues. An occupational therapist assigned to the team empowered staff to utilise equipment to improve patient care. CSWs also supported other departments in-between with administration tasks where possible. The CSWs were included in all patient discussions and attended handovers, team meetings and were offered clinical supervision/debrief sessions.

Conclusion The community team continued to provide highquality palliative care services as contracted even through the fast-paced changes. Patients and their carers reported feeling supported. The 'walls' around different hospice teams began to disintegrate with an appreciation of how the teams are all working to meet the shared aims of excellent patient-centred care. The pandemic has united the community team and forged strong links with other hospice teams. The CSWs developed their care and communication skills and the whole team have shown themselves to be non-judgemental, enthusiastic, and proud to serve their community.

\section{P-73 SHARING IS CARING - PEER TO PEER EDUCATION}

Fiona Irvine. Ayrshire Hospice, Ayr, UK

10.1136/spcare-2021-Hospice.91

Background During the COVID-19 pandemic Ayrshire Hospice piloted a training course for personal carers in North Ayrshire focusing on palliative and end-of-life care. The course was delivered online, comprising four 90 minutes sessions. One of the sessions focused specifically on the practical aspects of carrying out personal care towards the end of a person's life, and featured a demonstration by two of the hospice's senior care assistants using a training mannequin.

Aims The pilot aimed to increase knowledge and understanding of the principles of palliative and end-of-life care for personal carers. The aim of this particular session was to share, peer to peer, the specialist knowledge and skills required in caring for someone towards the end of their life.

Methods During this particular session, two experienced senior care assistants gave a practical demonstration of how they would provide personal care for someone nearing the end of their life, using a mannequin. They shared the practical skills they employ, emphasising the importance of care being carried out gently and slowly, and discussed how they used this as an opportunity to simultaneously assess the person's condition; looking for any signs of distress, pain, issues regarding skin integrity and oral health.

Outcomes Sharing best practice through example peer to peer was well received. Ultimately this will benefit the people being cared for, whilst also building the skills and confidence of all involved. Links were formed, with the hospice now viewed as an invaluable resource. The online nature of the training proved successful, in terms of ease of access for participants, and the flexibility to include demonstrations from hospice team members. Sessions evaluated positively. Further training has since been progressed in North Ayrshire, with the hope that it will be adopted across Ayrshire over the next 18 months.

\section{P-74 FAMILY AND COMMUNITY SUPPORT SERVICE - THE COMPASSIONATE COMMUNITIES APPROACH}

Maz Kull, Marianne Grant. Compton Care, Wolverhampton, UK

10.1136/spcare-2021-Hospice.92

Background The Family and Community Support Service was developed in response to the COVID-19 pandemic. By bringing together the Community Development, Social Work, Bereavement and Psychological Therapies Teams with the intention of extending our reach into communities for people affected by COVID-19, not known to Compton Care or living with a complex or incurable condition.

Aims To provide a support service for communities impacted by COVID-19 and focusing on three specific areas of support:

1. Wellbeing and Bereavement - Virtual Bereavement Information Hubs; a suite of bereavement literature; bereavement support through group sessions, art therapy and one-to-one counselling/therapy; virtual sessions on planning for the future.

2. Social isolation - Telephone befriending and virtual community support groups.

3. Signposting to other services - Information and guidance to help people access other services locally.

Methodology A triage and referral pathway developed through Compton Care Coordination Team to assess and identify the appropriate level of support for either informal, practical or complex support. Step 1 of the service to provide informal support to people in the community:

- Virtual Bereavement Information Hub - opportunity to share experience with others who are affected by loss and grief.

- Telephone befriending - supporting individuals on the telephone for those affected by loneliness and isolation.

- Understanding bereavement workshop - awareness session exploring effects of grief and supporting people who are grieving.

Results Through these methods, we have increased our community reach and supported the following:

- Virtual Bereavement Information Hub $=108$ sessions held/22 people making over 220 visits to a session.

- Telephone befriending $=37$ people and over 200 calls made.

- Understanding bereavement workshops = $12 \mathrm{held} / 78$ participants. 